\title{
Factor IX p.A37V mutation causes severe bleeding in a patient with phenprocoumon therapy
}

Nils Mülling ${ }^{1}$, Vivian Rosery ${ }^{2}$, H. Christian Reinhardt ${ }^{3}$ and Maher Hanoun ${ }^{3^{*}}$ (])

\begin{abstract}
Background: Bleeding is the most common complication of oral anticoagulants, due to inadequate dosing.

Case presentation: This report describes the clinical course of a patient who developed severe bleeding under therapy with phenprocoumon, despite an INR in the lower therapeutic range. Strikingly, aPTT was prolonged, while factor IX activity was significantly reduced. Acquired hemophilia was excluded, due to missing detection of inhibitors. Finally, sequencing part of the factor IX gene including nucleotide position c.110 revealed a hemizygous factor IX mutation c.110C > T p (Ala37Val).

Conclusions: In rare cases, missense mutations in factor IX propeptide are associated with severe bleeding complications. The substitution of alanin at position 37 to either valin or threonin (Ala37Val or Ala37Thr) leads to hypersensitivity to vitamin $k$ antagonists.
\end{abstract}

Keywords: Vitamin Kantagonists, Bleeding, Acquired hemophilia, Factor IX mutation

\section{Background}

Bleeding is the most common complication of oral anticoagulants, due to inadequate dosing. This report describes the clinical course of a patient who developed severe bleeding under therapy with phenprocoumon, despite an INR in the lower therapeutic range. Strikingly, aPTT was prolonged, while factor IX activity was significantly reduced. Acquired hemophilia was excluded, due to missing detection of inhibitors. In rare cases, missense mutations in factor IX propeptide are associated with severe bleeding complications [1]. The substitution of alanin at position 37 to either valin or threonin (Ala37Val or Ala37Thr) leads to hypersensitivity to vitamin $k$ antagonists $[1,2]$.

\footnotetext{
*Correspondence: maher.hanoun@uk-essen.de

${ }^{3}$ Department of Hematology and Stem Cell Transplantation, University Hospital Essen, University Duisburg-Essen, Hufelandstr. 55, 45147 Essen, Germany

Full list of author information is available at the end of the article
}

\section{Case presentation}

A 55-year-old male patient was admitted to an external hospital with deterioration in general condition and dyspnea. A few months earlier, the patient underwent mechanical aortic valve replacement, due to infective endocarditis and hereafter received phenprocoumon. During the inpatient stay, hemoglobin levels dropped from 10.2 to $3.9 \mathrm{~g} / \mathrm{dl}$. While INR was with 2.29 in lower therapeutic range, aPTT was significantly increased reaching 104 s (Table 1). Computed tomography showed pronounced retroperitoneal hemorrhage. After repeated bleeding and surgical interventions, the patient was referred to our department. Here, he presented with spontaneous bleeding into the left psoas major, iliacus muscle and the left thigh (Fig. 1A). Phenprocoumon was paused and substituted by unfractionated heparin. After detecting a substantially reduced factor IX activity of $3 \%$, mixing studies were performed, showing a gradual normalization of factor IX activity, two hours after incubation with increasing doses of normal plasma. Together

c) The Author(s) 2021. This article is licensed under a Creative Commons Attribution 4.0 International License, which permits use, sharing, adaptation, distribution and reproduction in any medium or format, as long as you give appropriate credit to the original author(s) and the source, provide a link to the Creative Commons licence, and indicate if changes were made. The images or other third party material in this article are included in the article's Creative Commons licence, unless indicated otherwise in a credit line to the material. If material is not included in the article's Creative Commons licence and your intended use is not permitted by statutory regulation or exceeds the permitted use, you will need to obtain permission directly from the copyright holder. To view a copy of this licence, visit http://creativeco mmons.org/licenses/by/4.0/. The Creative Commons Public Domain Dedication waiver (http://creativecommons.org/publicdomain/ zero/1.0/) applies to the data made available in this article, unless otherwise stated in a credit line to the data. 
Table 1 aPTT, thrombocytes, prothrombin time, INR and activities of the measured coagulation factors at time of the bleeding

\begin{tabular}{lll}
\hline Parameter & Result & Normal range \\
\hline Thrombocytes $\left(10^{3} / \mu\right.$ l) & 439 & $163-337$ \\
Prothrombin time $(\%)^{\mathrm{a}}$ & 34 & $70-130$ \\
INR & 2.29 & $0.8-1.2$ \\
aPTT (s) & 104 & $23.6-34.8$ \\
Factor VIII (\%) & 246 & $80-216$ \\
Factor IX (\%) & 3 & $78-150$ \\
Factor XI (\%) & 111 & $83-154$ \\
Factor XII (\%) & 72 & $>53$ \\
Factor XIII (\%) & 78 & $>86$ \\
\hline
\end{tabular}

${ }^{\text {a }}$ Prothrombin time expressed as percent according to Quick with missing detection of inhibitors, acquired hemophilia could be ruled out. After cessation of phenprocoumon and application of unfractionated heparin, factor IX activity recovered gradually within approximately 10 days. The patient then resumed treatment with phenprocoumon. However, within few days factor IX activity rapidly dropped and this was reproduced in a second approach (Fig. 1B). Finally, sequencing part of the factor IX gene, including nucleotide position c.110 revealed a hemizygous factor IX mutation c.110C $>\mathrm{T} p$ (Ala37Val). Anticoagulation has subsequently been continued with low molecular weight heparin under close monitoring of anti-factor Xa activity and regular cardiovascular examinations. Factor IX activity remained within normal range, no further relevant bleeding or thromboembolic events

\section{A}

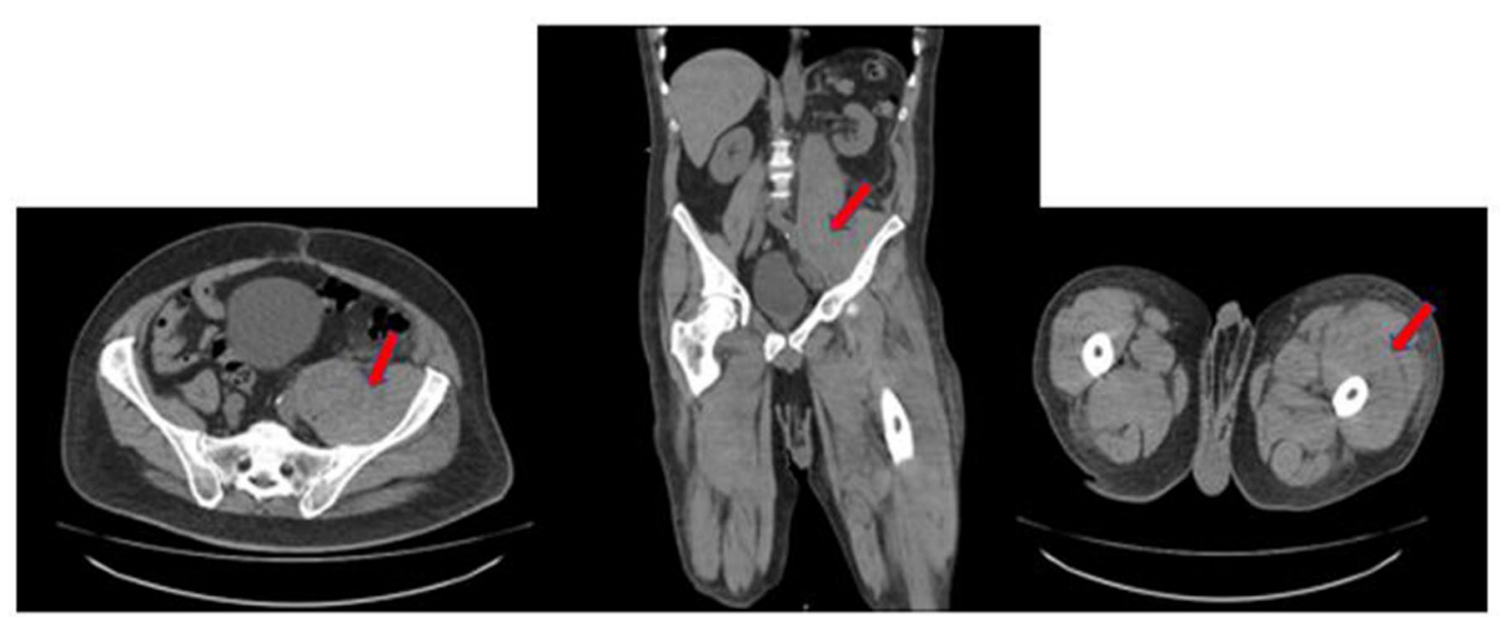

B

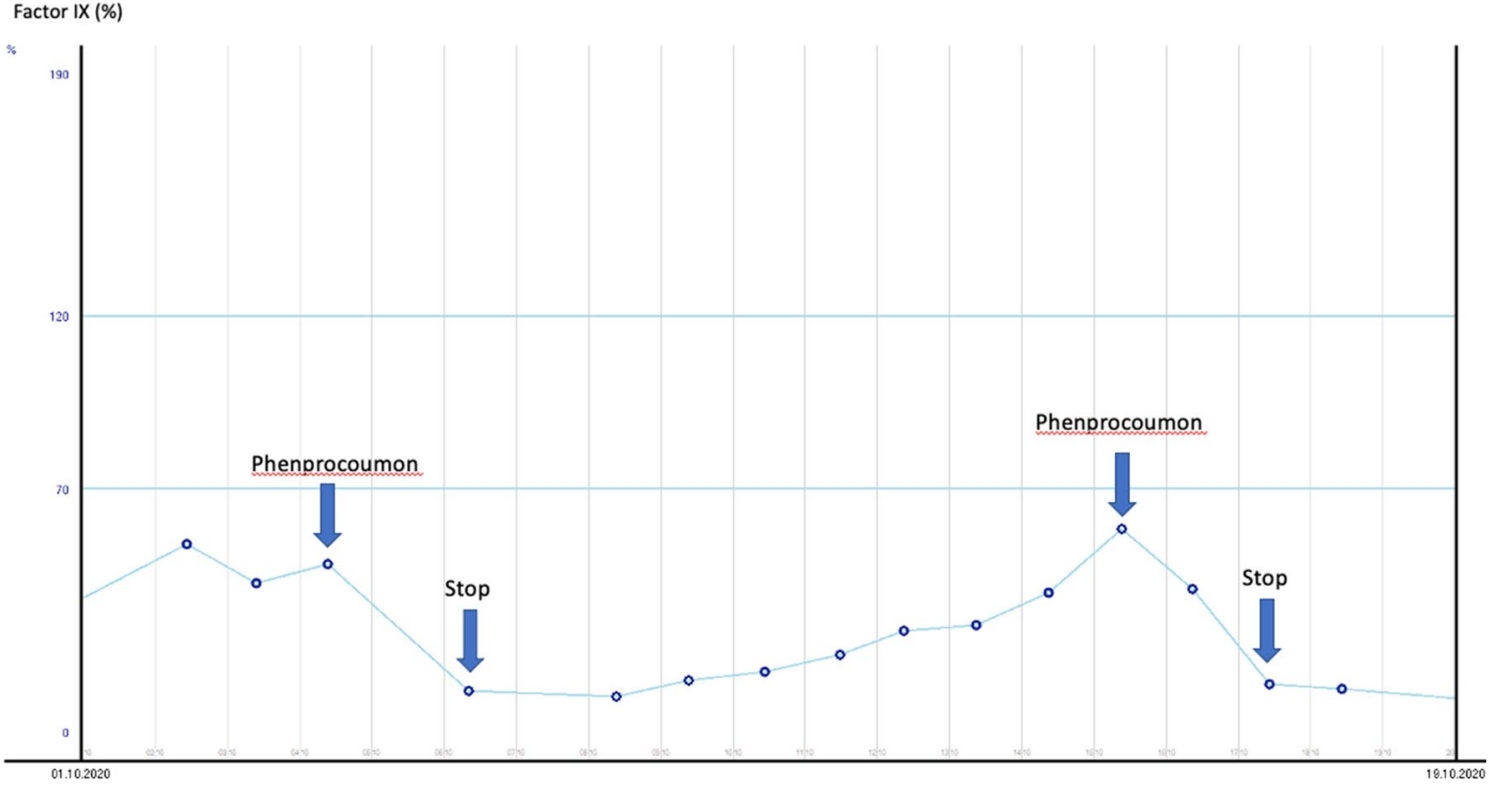

Fig. 1 A CT images (native investigation) demonstrating severe hemorrhage into left psoas major, iliacus muscle and left thigh, indicated by the red arrows. B Factor IX activity during phenprocoumon rechallenge. "Stop" indicates discontinuation of treatment 
occurred. Replacing the mechanical aortic valve with a biological valve is still under evaluation.

\section{Discussion and conclusions}

Bleeding is a major complication of treatment with phenprocoumon in case of overdose [3]. Bleeding complications with isolated prolongation of aPTT are suggestive for acquired hemophilia, which is induced by inhibitory autoantibodies [4]. Mixing studies confirm the diagnosis, as a small proportion of normal plasma compensates for clotting factor deficiency and normalizes clotting time. However, in the presence of inhibitors, normalization does not occur even with higher doses of normal plasma [4]. The gene encoding for factor IX is located on the long arm of the $\mathrm{X}$ chromosome (Xq27.1). Two missense mutations in the factor IX propeptide coding region at the Ala-10 residue have been described for an exchange of alanine (GCC) to valine (GCT) or threonine (ACC) [1]. In our case, the Ala-10 [GCC] to Val [GCT] mutation was detected. These mutations lead to hypersensitivity of factor IX to vitamin $\mathrm{K}$ antagonists as the -10 position of the factor IX propeptide contains the binding site for $\gamma$-carboxylase. An amino acid exchange at this point leads to significantly reduced binding affinity of factor IX for $\gamma$-carboxylase. Under normal conditions, this induces a slight reduction in factor IX activity without clinical relevance. However, in case of oral anticoagulation with vitamin $\mathrm{K}$ antagonists, lack of biologically active vitamin $\mathrm{K}$ combined with reduced affinity of factor IX propeptide for $\gamma$-carboxylase leads to a clinically relevant decrease in factor IX activity with high risk of bleeding [5]. There is only imprecise information on the prevalence of factor IX germline mutations. Previously, the examination of 255 unrelated X-chromosomes for the presence of factor IX mutation did not reveal any case. The authors estimated a prevalence below $1.46 \%$ at $95 \%$ confidence interval [1]. Ulrich et al. extrapolated the prevalence in Switzerland at 1: 10,000 to 1: 100,000 [2]. On top, only rare cases of severe bleeding events in patients carrying factor IX mutation have been reported $[1,2,5,6]$.

This report highlights that aPTT should be determined in patients with an unclear bleeding event under therapy with vitamin $\mathrm{K}$ antagonists. In cases of a significantly prolonged aPTT, factor IX mutations should be excluded [2].

\section{Authors' contributions}

$\mathrm{NM}, \mathrm{VR}, \mathrm{HCR}$, and $\mathrm{MH}$ analyzed and interpreted the patient data and wrote the manuscript. All authors read and approved the final manuscript for publication.

Funding

Open Access funding enabled and organized by Projekt DEAL.

Availability of data and materials

Not applicable.

\section{Declarations}

Ethics approval and consent to participate

The patient has given written informed consent to publish his case including publication of images.

\section{Competing interests}

The authors declare that they have no competing interests.

\section{Author details}

${ }^{1}$ Department of Nephrology, University Hospital Essen, University DuisburgEssen, Hufelandstr. 55, 45147 Essen, Germany. ${ }^{2}$ Clinic for Internal Medicine (Tumor Research), University Hospital Essen, University Duisburg-Essen, Hufelandstr. 55, 45147 Essen, Germany. ${ }^{3}$ Department of Hematology and Stem Cell Transplantation, University Hospital Essen, University Duisburg-Essen, Hufelandstr. 55, 45147 Essen, Germany.

Received: 18 May 2021 Accepted: 14 June 2021

Published online: 29 June 2021

\section{References}

1. Oldenburg J, Quenzel EM, Harbrecht U, Fregin A, Kress W, Muller CR, et al. Missense mutations at ALA-10 in the factor IX propeptide: an insignificant variant in normal life but a decisive cause of bleeding during oral anticoagulant therapy. Br J Haematol. 1997;98(1):240-4.

2. Ulrich S, Brand B, Speich R, Oldenburg J, Asmis L. Congenital hypersensitivity to vitamin $\mathrm{K}$ antagonists due to FIX propeptide mutation at locus10: a (not so) rare cause of bleeding under oral anticoagulant therapy in Switzerland. Swiss Med Wkly. 2008;138(7-8):100-7.

3. Hirsh J. Oral anticoagulant drugs. N Engl J Med. 1991;324(26):1865-75.

4. Kruse-Jarres R, Kempton CL, Baudo F, Collins PW, Knoebl P, Leissinger CA, et al. Acquired hemophilia A: updated review of evidence and treatment guidance. Am J Hematol. 2017:92(7):695-705.

5. Pezeshkpoor B, Czogalla KJ, Caspers M, Berkemeier AC, Liphardt K, Ghosh $\mathrm{S}$, et al. Variants in FIX propeptide associated with vitamin $\mathrm{K}$ antagonist hypersensitivity: functional analysis and additional data confirming the common founder mutations. Ann Hematol. 2018;97(6):1061-9.

6. Kristensen SR. Warfarin treatment of a patient with coagulation factor IX propeptide mutation causing warfarin hypersensitivity. Blood. 2002;100(7):2676-7.

\section{Publisher's Note}

Springer Nature remains neutral with regard to jurisdictional claims in published maps and institutional affiliations. 